\title{
Design and implementation a security system for bank using voice recognition
}

Mohammed Hasan Ali, Qasim Al Azze

Department of Electrical Power and Machines, Collage of Engineering, University of Diyala, Iraq

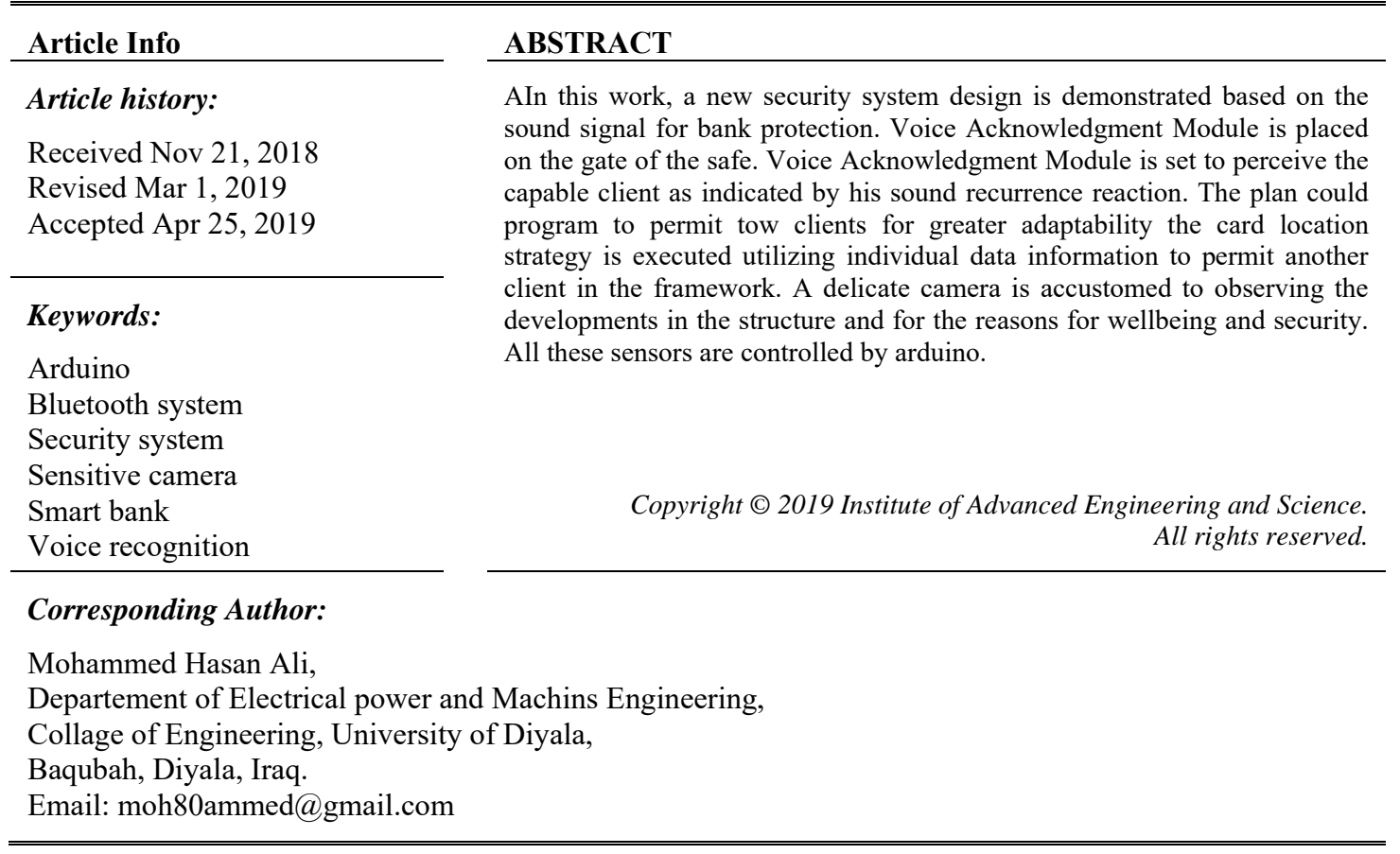

\section{INTRODUCTION}

In this work at the present age, wellbeing has turns into an essential issue for the majority of the general population for amost part in the provincial and urban territories [1]. A few people are worry about their wellbeing for their costly thing like adornments cash and so on. So, bank locker is the most secure place to amass them however the customary security framework isn't giving the higher security in light of the fact that in traditional security framework a client can open the lockers utilizing keys $[2,3]$. At that point the client will apply for unique keys yet the day and age are longer to get started new keys so in its place of utilizing this security framework I have executed. In this present age, wellbeing has turns into a vital issue for GSM based security framework which give greater security then traditional framework [4]. The paper is present an actualized security of cash in the bank saving, resident or working environment (treasury) by utilizing sound sensor and GSM innovation, that is more ensured than different frameworks. In this paper, single sound sensor module is utilized for check on or to approve people to open the different bank locker with GSM innovation. In this paper I have planned and executed a bank locker security framework in view of sound sensor and GSM innovation. In this framework just valid individual can be recouped cash from building lockers with secret word insurance strategy [5]. I outlined delicate camera used to checking the developments in the building and for the reasons for wellbeing and security; which is sending a flag to control the electric power in the building and if there should be an occurrence of caution fire [6, 7].

\section{MODEL OF BANK}

The model of bank has been portrayed as the joining of advancement and organization through a bank system for a predominant individual fulfilment appeared in Figure 1. It has been using impelled PC and 
framework correspondences development, fused wiring advancement normally solidified with all subsystems, Entryway Bolt structure Utilizing sound sensor development [8]. Bank has been around for quite a while and things have been open for a broad number of years, be that as it may, nobody's strategy has turned out to be through to the standard yet. The astute bank uses the control structures and information advancements to diminish the prerequisite for human work in the age of stock and undertakings. A sagacious bank consolidates distinctive sub-systems that are out and out controlled by a pro bank controller [9, 10].

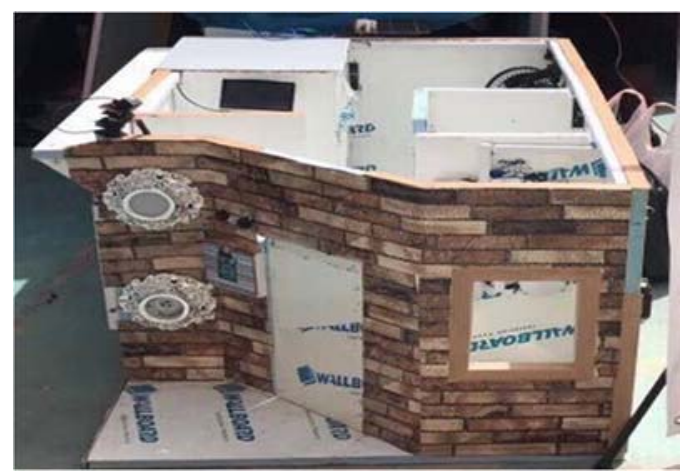

Figure 1. Model of bank

\section{VOICE ACKNOWLEDGMENT MODULE}

Voice Recognition is a biometric innovation which is utilized to perceive a specific individual voice. The discourse waves of specific voice structure the premise of distinguishing proof of speaker [11] shown in Figure 2. We can utilize voice ID in numerous application territories such as phone banking, shopping through phone, access to database data and voice message [12]. One of the ground-breaking uses of voice acknowledgment is for security reason where an individual can enter his/her voice for verification. Each kind of voice has its exceptional qualities called highlight and the way toward removing these highlights from the individual voice is called highlight extraction. The voice highlights which are removed are contrasted and right now spared voices in the database for coordinating $[13,14]$.

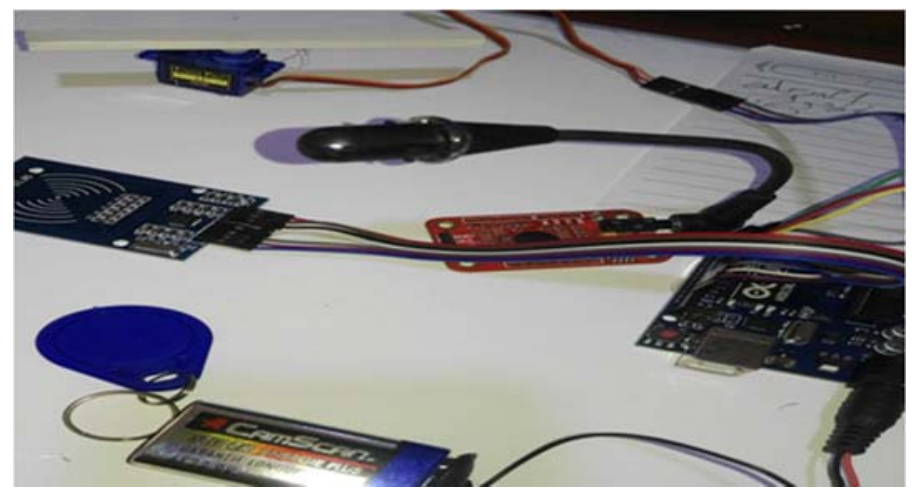

Figure 2. Voice recognition

\section{RESULTS}

In the private part, it has successfully controlled the dual control process with bank, lighting and other Smartphones using mobile represented applications that have been designed for this purpose where the control and operation/shutting off the device itself is either by a connection using Bluetooth. It is controlled by application Bluetooth or by means of a local or internal Wi-Fi connection, or by global IP.

It is controlled by the IoT application. Where the same device is turned off or operated from any application either by employing wifi or Bluetooth. shown in Figure 3.

Design and implementation a security system for bank using voice recognition ... (Mohammed Hasan Ali) 
Voice Acknowledgment Module is a board that control and response according to talking acknowledgment as shown in Figure 4. This module is a speaker-subordinate voice acknowledgment. On the whole, the module is supported up to 80 voice charges. In meantime, a max of seven voice summonses could be worked. Any sound can prepare as summon. Where, clients firstly have to prepare the module, after that module can receive any voice order.

The modular is controlled from two way; general information pins (some portion of capacity) and serial port (full capacity). On modular board, general yield sticks can produce limited sorts of waves, whereas relating voice summon was perceived as appeared in Figure 5.

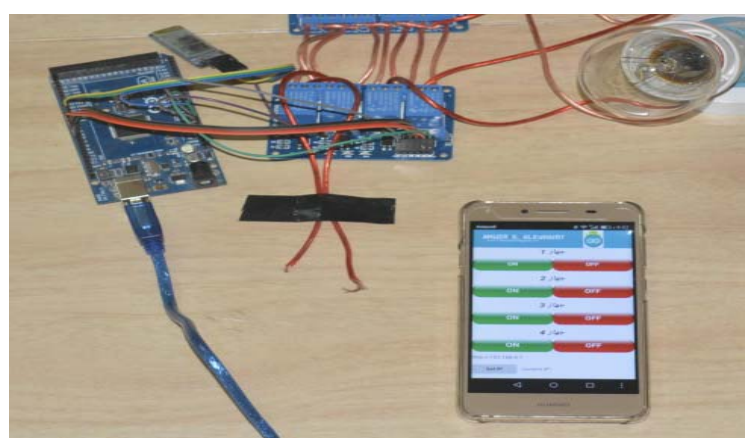

Figure 3. Bluetooth and wifi module

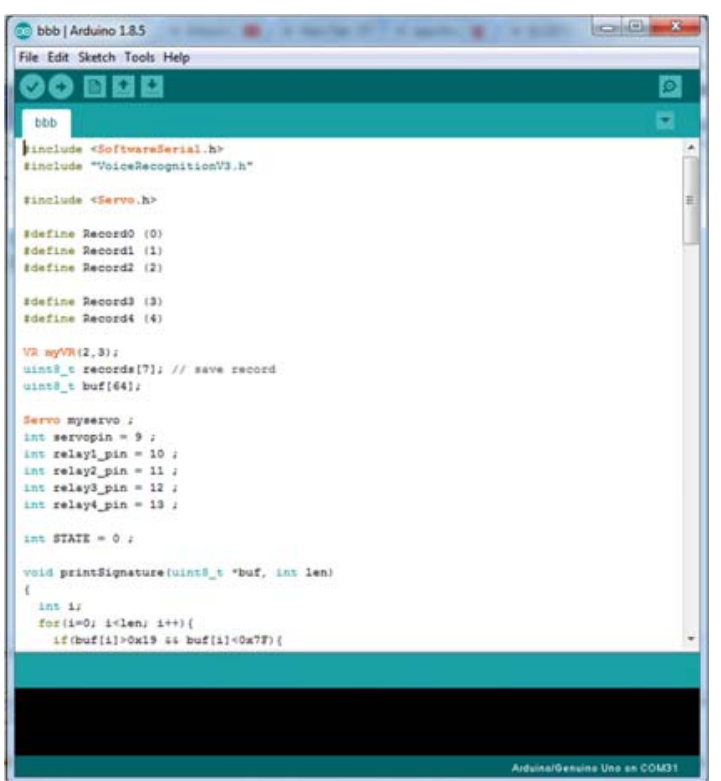

Figure 4. Code of voice recognition added

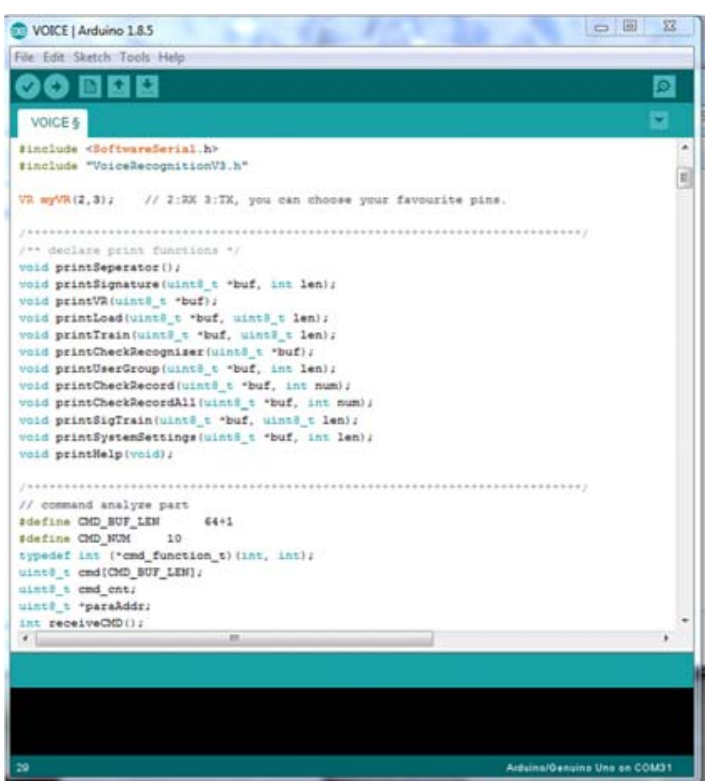

Figure 5. Code of voice recognition operation

\section{CONCLUSION}

It can be reasoned that IOT Based Security System and Intelligent that Design and usage security framework for bank utilizing sound sensor was a win. The plan of sharp control contains Arduino sheets, sound sensor, a Bluetooth Module, touchy camera, Android application For the Bluetooth technique and application. Moreover, the System of sound sensor Security and Access Control System includes an Arduino board, RFID module, Servo Motor, Red LED, Blue LED and a Buzzer. Likewise, the delicate camera includes an Arduino Uno, Ultrasonic sensor, Bluetooth module, Relay module and Android Smart phone Smart Lighting structure involves PIR sensor and a Relay. It is anything but difficult to utilize and temperate.

Int J Pow Elec \& Dri Syst Vol. 10, No. 4, Dec 2019 : 2126 - 2129 


\section{FUTURE RECOMMENDATIONS}

Future work recommendations may be including, the possibility of using Raspberry to develop work. Attempt to develop the security system with using advance cameras which to connect the internet which is sent by SMS to the security center. Possibility of adding new sensors to increase protection.

\section{REFERENCES}

[1] Hsien-Tang Lin, "Implementing Smart Homes with Open Source Solutions," International Journal of Smart Home, vol. 7, no. 4, pp 289-295, 2013.

[2] Gowthami, Dr. Adiline macriga, "Smart Home Monitoring and Con trolling System Using Android Phone," International Journal of Emerg-ing Technology and Advanced Engineering, vol. 3, no. 11, 2013.

[3] Ali, Mohammed Hasan, "Design and Implementation of an Electrical Lift Controlled using PLC," International Journal of Electrical and Computer Engineering (IJECE), vol. 8, no. 4, p. 1947, 2018.

[4] A. Z. Alkar and U. Buhur, "An internet-based wireless home automation system for multifunctional devices," IEEE Transactions on Consumer Electronics, vol. 51, pp. 1169-1174, 2005.

[5] R. Shahriyar, E. Hoque, S. Sohan, I. Naim, M. M. Akbar, and M. K. Khan, "Remote controlling of home appliances using mobile telephony," International Journal of Smart Home, vol. 2, pp. 37-54, 2008.

[6] Sagar S. Palsodkar, Prof S.B Patil, "Biometric and GSM Based Security for lockers," International Journal of Engineering Research and Application, vol. 4, 2014.

[7] Christian Reinisch, Mario J. Kofler, Wolfgang Kastner, "ThinkHome: A Smart Home as Digital Ecosystem," 4th IEEE International Confe-rence on Digital Ecosystems and Technologies (IEEE DEST 2010), 2010.

[8] Ali, Mohammed H., "Mathematical Driving Model of Three Phase, Two Level Inverter by (Method of Interconnected Subsystem)," Iraqi Journal for Electrical and Electronic Engineering, vol.13, no.1, pp. 73-82, 2017.

[9] R. Piyare and M. Tazil, "Bluetooth based home automation system using cell phone," in Consumer Electronics (ISCE), 2011 IEEE 15th International Symposium, pp. 192-195, 2011.

[10] A. Aditya Shankar, P.R.K. Sastry, A.L. Vishnu ram.A. Vamsidhar, "Fingerprint Based Door Locking System," International Journal of Engineering and Computer Sciences, vol. 4, no. 3, 2015.

[11] M. Gayathri, P. Selvakumari, R. Brindha, "Fingerprint and GSM based Security System," International Journal of Engineering Sciences Research Technology, vol. 3(4), 2014.

[12] Benyahia, Ismahane, Mohammed Beladgham, and Abdesselam Bassou, "Evaluation of the Medical Image Compression using Wavelet Packet Transform and SPIHT Coding," International Journal of Electrical and Computer Engineering (IJECE), vol. 8, no. 4, p. 2139, 2018.

[13] Bhuyan, Sujit Kumar, Prakash Kumar Hota, and Bhagabat Panda, "Modeling, Control and Power Management Strategy of a Grid connected Hybrid Energy System," International Journal of Electrical and Computer Engineering (IJECE), vol. 8, no. 3, p. 1345, 2018.

[14] Mengistu, Abrham Debasu, "The Effects of Segmentation Techniques in Digital Image Based Identification of Ethiopian Coffee Variety," TELKOMNIKA (Telecommunication, Computing, Electronics and Control), vol. 16, no. 2, pp. 713-717, 2018.

\section{BIBLIOGRAPHY OF AUTHORS}
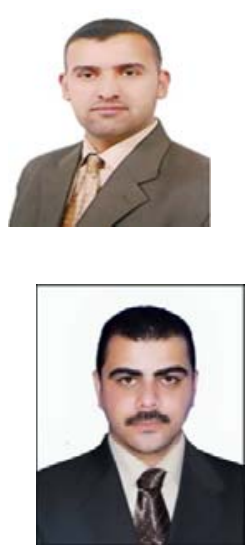

Mohammed Hasan Ali was born in Diyala, Iraq, in 1980, received his B.Sc. from University Diyala / Iraq in 2006, M. Sc. from University of Belgorod, Russia ,2013 .He is currently assistant lecturer at the Department of Electrical Power Engineering, College of Engineering, University of Diyala Iraq. Professional Strength and Skills: His current research interests are power system modeling, power quality, renewable energy and power electronics. He has 10 years experience in practice of Electrical engineering. He is teaching several basic subjects of the Electrical Engineering, University of Diyala Iraq. He has 4 published papers.

Master Degree of Electrical Engineering from Southern Illinois University Edwardsville (SIUE) from United States of America, in 2014, in area of Electrical Power and Control Machines Engineering. Bachelor Degree of Electrical Power and Machines Engineering from University of Diyala, College of Engineering, Iraq, in 2005.

- Currently, instructing Electrical Machines and Drives Course in Dep. of Electrical Power and Machines, As well Electrical Engineering course in Mechanical Engineering Department. Previously, Instructing some courses and graduated projects in Dep. of Electrical Power and Machines

- $\quad$ Skills; Using Text Maker, MatLab, MS Offices, programing some type of Microcontroller in order to build power electronic deriver like converter two directions.

- Area of Interesting; Power System, Power Electronics, Automatic Control, Electrical Machines and Drives, Renewable Energy, Smart Grid, and HVDC, Hybrid Vehicles and Electric Vehicles. 